\section{Neuroblastoma with orbital metastasis: ophthalmic presentation and role of ophthalmologists}

S Ahmed, S Goel, M Khandwala, A Agrawal, B Chang and IG Simmons
Ophthalmology

Department, Leeds Teaching Hospitals NHS Trust, Leeds, UK

Correspondence: S Ahmed, Leeds Teaching Hospitals NHS Trust, Department of Ophthalmology, Chancellor Wing, Beckett Street, Leeds LS9 7TF, UK

Tel: + 441132064737 ;

Fax: + 441132064268 .

E-mail: suheb@

nhs.net

Received: 1 November 2004 Accepted: 17 March 2005 Published online: 13 May 2005

The authors have no financial or proprietary interests. This paper received no financial support from public/private bodies.

\begin{abstract}
Introduction Neuroblastoma is predominantly a tumour of early childhood, which metastasises to the orbits. In such cases, ophthalmologists are involved in the multidisciplinary management. This unique series from a tertiary referral centre is used to elaborate the ophthalmic associations and the ophthalmologist's role in this rare condition.

Methods A review of case notes was performed on six patients who presented to the paediatric ophthalmology - oncology liaison service at the Leeds teaching hospitals between 1998 and 2003. The ophthalmic outcome and role of the ophthalmologist were assessed.

Results Average age of presentation was 29.8 months (range 15-69 months). Average duration of follow-up was 19.5 months (range 2-58 months). One child died during treatment. Two have completed treatment and are under follow-up. Presenting features of the six children were proptosis in four, periorbital ecchymosis in two, ocular motility restriction in two, and subconjunctival haemorrhage in one. Only one case developed blindness. Conclusions The role of the ophthalmologist in patients with metastatic orbital neuroblastoma can vary from a supportive role to one of active intervention and management of ophthalmic complications. The ophthalmologist is involved in diagnosis and staging as well as monitoring response to treatment of both the primary disease and secondary ophthalmic complications.

Eye (2006) 20, 466-470. doi:10.1038/sj.eye.6701912; published online 13 May 2005

Keywords: orbital; neuroblastoma; ophthalmology; metastasis
\end{abstract}

Introduction

Neuroblastoma is an uncommon tumour of childhood occurring in about nine cases per million children. It constitutes about $7.5 \%$ of all cancers occurring in children less than 15 years of age, indicating its small but significant presence as a childhood tumour. ${ }^{1}$ In all, $90 \%$ of all neuroblastomas occur before 10 years of age. ${ }^{1}$ Rapid developments are being made towards the diagnosis and medical management of the disease. Various gene markers are evolving as useful prognostic and resolution indicators. In the midst of these developments while ophthalmic involvement is recognised as a part of the disease process, very little published data is available detailing the ophthalmic disease spectrum and the role of the ophthalmologist.

In this paper, we examined the records of a small series of cases of neuroblastoma with orbital metastasis. The objective was to analyse the role of the ophthalmology service in such cases, the spectrum of presentation of the disease, the complications of treatment, and final outcome.

\section{Methods}

Six patients aged 15-69 months who presented to the paediatric ophthalmology - oncology liaison service at the Leeds Teaching Hospitals NHS Trust between 1998 and 2003 had case notes reviewed. All cases were identified from an electronic database of all neuroblastoma patients seen by the paediatric oncology service. The modes of presentation, role of the ophthalmology team, and outcomes are assessed and discussed. 


\section{Results}

In all, 48 cases of neuroblastoma were seen between 1998 and 2003. Of these, $15(31 \%)$ had head and neck metastases with six $(12.5 \%)$ having orbital metastases. Two of the six children were girls, giving a male to female ratio of $2: 1$. The average age of presentation was 29.8 months (15-69 months). The average duration of follow-up was 19.5 months (range 2-58 months). All of the children were treated as part of a United Kingdom Children's Cancer Study Group (UKCCSG) trial undergoing chemotherapy. The complications of treatment were sensorineural hearing loss and developmental delay in one child and optic atrophy due to orbital cellulitis in another.

Two of the children had completed all treatment and were under observational follow-up. One child had died while undergoing chemotherapy. The other three were at different stages of the treatment cycle.

Table 1 Summary of patient characteristics

\begin{tabular}{|c|c|c|c|c|}
\hline $\begin{array}{l}\text { Case } \\
\text { no. }\end{array}$ & $\begin{array}{c}\text { Age } \\
\text { (months) }\end{array}$ & Gender & Primary site & Ophthalmic Site \\
\hline 1 & 48 & $\mathrm{~F}$ & Left adrenal & Right orbit (Figure 1) \\
\hline 2 & 15 & $\mathrm{~F}$ & $\begin{array}{l}\text { Left } \\
\text { paravertebral } \\
\text { mass } \\
\text { (Figure 2b) }\end{array}$ & Left orbit (Figure 2a) \\
\hline 3 & 17 & $\mathrm{M}$ & Right adrenal & Left orbit (Figure 3) \\
\hline 4 & 69 & $\mathrm{M}$ & Right adrenal & $\begin{array}{l}\text { Left orbit (Figure } 4 a \\
\text { and } 4 b \text { ) }\end{array}$ \\
\hline 5 & 10 & $\mathrm{M}$ & Left adrenal & Right orbit (Figure 5) \\
\hline 6 & 20 & $\mathrm{M}$ & Left adrenal & Left orbit \\
\hline
\end{tabular}

$\mathrm{F}=$ female; $\mathrm{M}=$ male.
The time taken from initial presentation to a documented diagnosis of neuroblastoma varied from 1 day to 6 weeks (median $=3$ days). The longer time interval represents a child (case 2) who did not present with proptosis. In five of the six children, the metastases originated from the adrenal glands. The exception was a child (case 2) with a paravertebral thoracic neuroblastoma.

Four of the six children $(67 \%)$ presented with proptosis. Two of the children (33\%) had restricted ocular motility, two had periorbital ecchymosis (33\%), and only one had subconjunctival haemorrhage. One child had radiological evidence only of metastasis. None of the children had opsoclonus/myoclonus or Horner's syndrome. Among the children who presented with proptosis, one developed blindness in that eye (case 1).

Tables 1 and 2 provide a summary and allow for comparison of the six cases (Figures 1-5).

\section{Discussion}

Neuroblastoma is predominantly a tumour of early childhood and between 10-20\% of cases have orbital metastases. ${ }^{2-4}$ Neuroblastoma originates in the adrenal medulla or the paraspinal sites where sympathetic nervous system tissue is present. Symptoms are due to a tumour mass or bone pain from metastases. Proptosis and periorbital ecchymosis ('raccoon eyes') are common and arise from retrobulbar metastases. Extensive bone marrow metastases may result in pancytopenia and therefore subconjunctival haemorrhages. Paraneoplastic neurologic findings including cerebellar ataxia or opsoclonus/myoclonus (dancing eyes, dancing feet) may

Table 2 Summary of presenting symptoms, complications, and outcome

\begin{tabular}{|c|c|c|c|c|}
\hline $\begin{array}{l}\text { Case } \\
\text { no. }\end{array}$ & Ophthalmic presentation & Ophthalmic complication & Outcome & Ophthalmic Role \\
\hline 1 & $\begin{array}{l}\text { Proptosis, subconjunctival } \\
\text { haemorrhage }\end{array}$ & Orbital cellulitis, optic atrophy & $\begin{array}{l}\text { Blind right eye, under } \\
\text { treatment }\end{array}$ & $\begin{array}{l}\text { Diagnosis, biopsy, } \\
\text { monitoring during } \\
\text { treatment, treatment of } \\
\text { complications, visual } \\
\text { rehabilitation }\end{array}$ \\
\hline 2 & $\begin{array}{l}\text { Radiological evidence of orbital } \\
\text { metastasis }\end{array}$ & Nil & Under treatment & $\begin{array}{l}\text { Monitoring during } \\
\text { treatment }\end{array}$ \\
\hline 3 & $\begin{array}{l}\text { Proptosis, periobital ecchymosis, } \\
\text { ocular motility defect }\end{array}$ & Nil & $\begin{array}{l}\text { Hearing loss, developmental } \\
\text { delay, disease free }\end{array}$ & $\begin{array}{l}\text { Monitoring during } \\
\text { treatment }\end{array}$ \\
\hline 4 & Proptosis, ocular motility defect & Left amblyopia & Under treatment & $\begin{array}{l}\text { Monitoring during } \\
\text { treatment, treatment of } \\
\text { complications }\end{array}$ \\
\hline 5 & Proptosis & Right RAPD, reduced VA & Under treatment & $\begin{array}{l}\text { Monitoring during } \\
\text { treatment }\end{array}$ \\
\hline 6 & Periorbital ecchymosis & Nil & Died of disease & $\begin{array}{l}\text { Monitoring during } \\
\text { treatment }\end{array}$ \\
\hline
\end{tabular}

$\mathrm{VA}=$ visual acuity; $\mathrm{RAPD}=$ relative afferent papillary defect. 


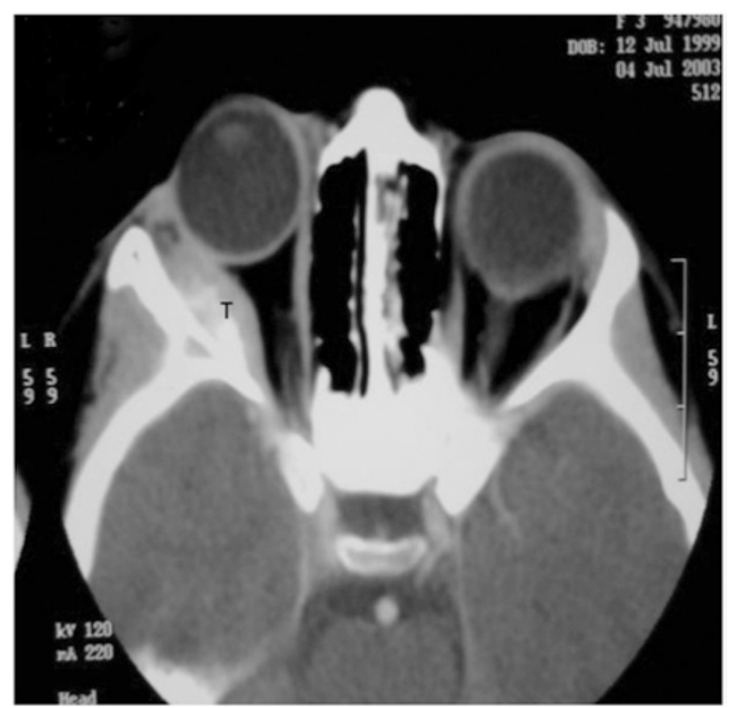

Figure 1 CT appearance of right lateral orbital mass ( $\mathrm{T}=$ tumour $)$
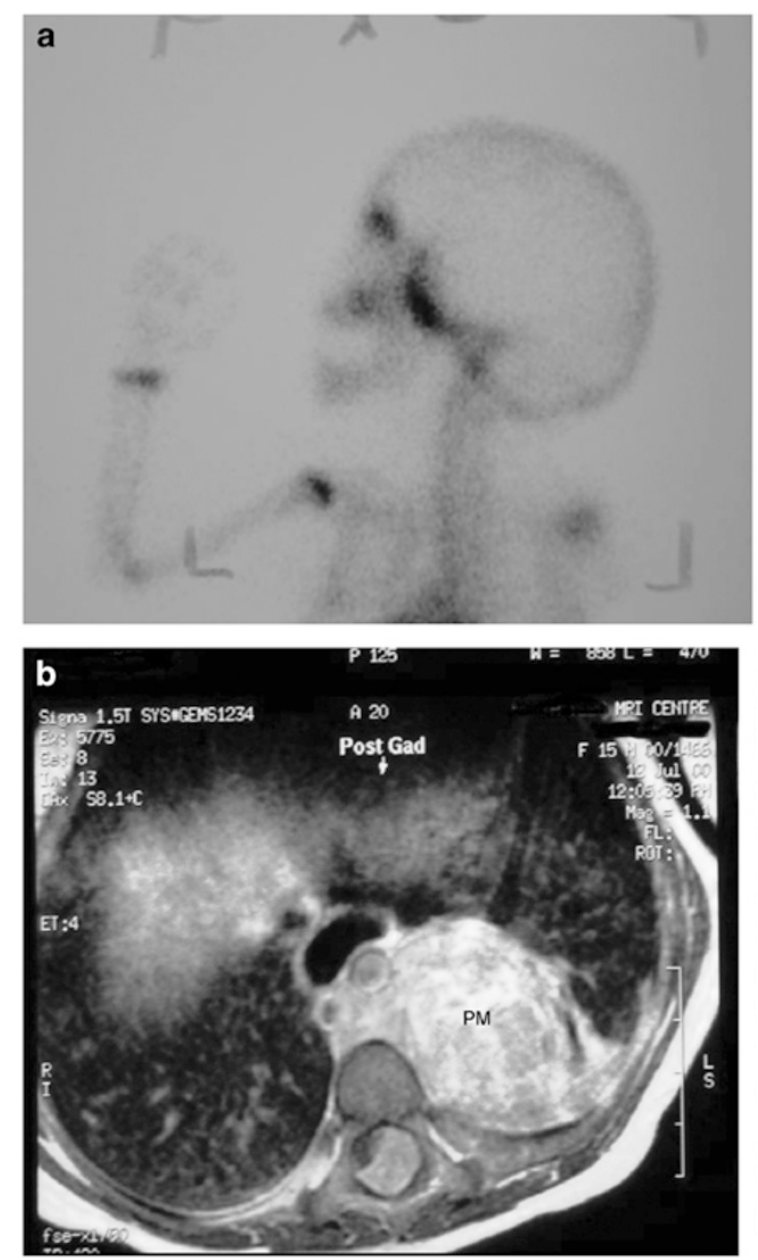

Figure 2 (a) Bone scan appearance of left orbital metastasis. (b) MRI of paravertebral mass filling spinal canal T6-9 (PM = paravertebral mass).

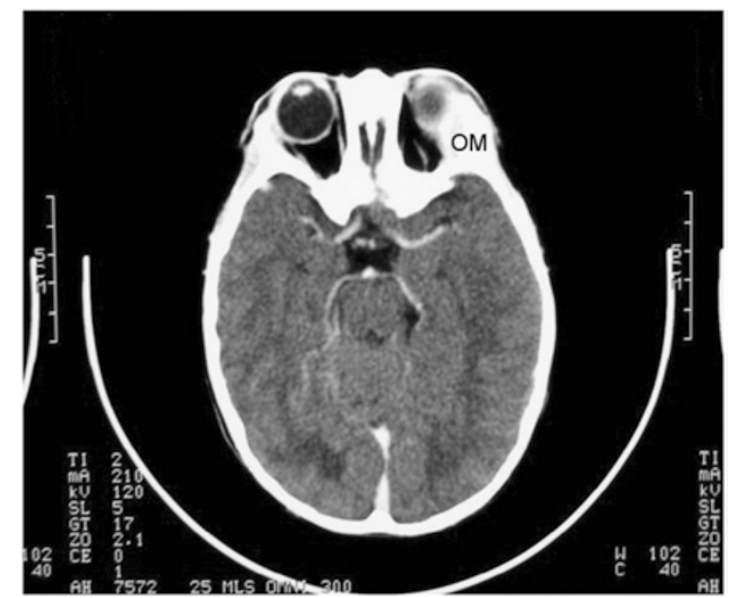

Figure 3 CT appearance of left supralateral orbital mass $(\mathrm{OM}=$ orbital mass $)$
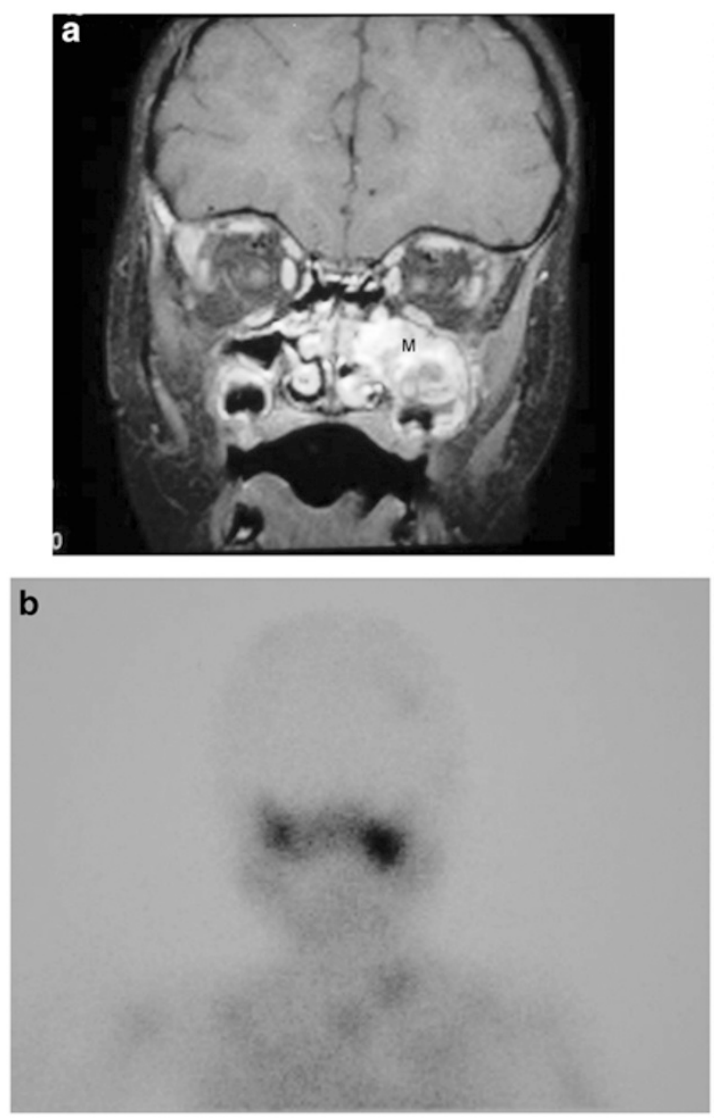

Figure 4 (a) MRI appearance of the metastatic tumour in the left maxillary antrum eroding into the orbit $(\mathrm{M}=$ mass). (b) Bone scan appearance of same tumour.

occur. ${ }^{5}$ Other manifestations include Horner's syndrome, aniscoria, and strabismus. ${ }^{2}$ Ophthalmic involvement by definition is Stage 4 disease according to the International Neuroblastoma Staging System. ${ }^{6}$ 


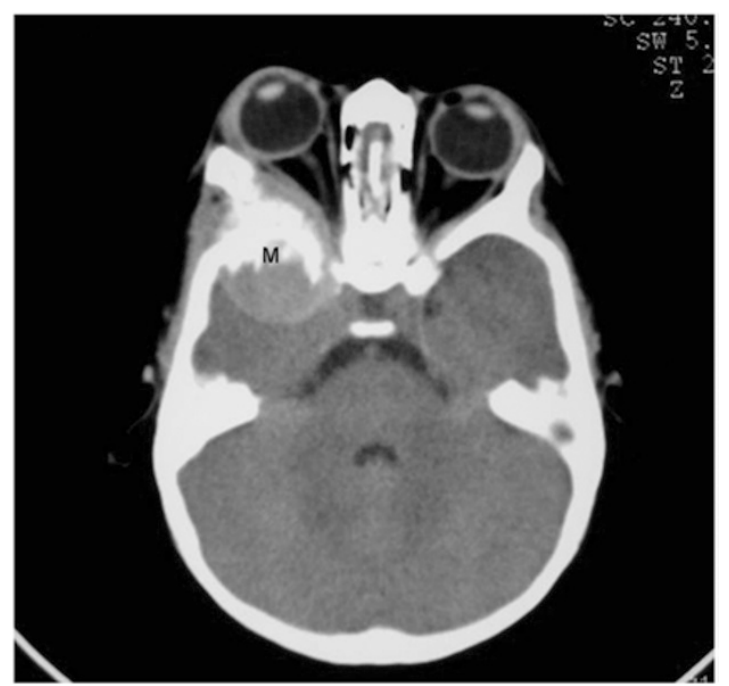

Figure $5 \mathrm{CT}$ appearance of soft tissue mass arising from the right greater wing of sphenoid $(\mathrm{M}=$ mass $)$.

Treatment of the primary disease is based on Children's Oncology Group Neuroblastoma Risk Group Assignment Schema of low, intermediate, or high. ${ }^{7}$ Orbital involvement falls in the high-risk category and therefore aggressive multiagent chemotherapy consisting of very high doses is employed. After a response to chemotherapy, resection of the primary tumour should be attempted, followed by myeloablative chemotherapy. Radiation therapy to the primary site may be indicated in high-risk patients. After recovery, patients are treated with oral 13-cis-retinoic acid for 6 months. Both myeloablative therapy and retinoic acid improve outcome in patients categorised as high risk. All of these treatments can have ophthalmic side effects, which may require the intervention of an ophthalmologist.

The series represents a 6-year experience of children with neuroblastoma with ophthalmic involvement at a regional teaching hospital. In all, $90 \%$ of the cases were in children younger than 10 years and all the cases in this study were within this age. ${ }^{1}$ The incidence of orbital metastasis at $12.5 \%$ is also in the published range of between 10 and 20\%. ${ }^{2-4}$ Although the male incidence is reported to be slightly higher, ${ }^{1}$ the male to female ratio of $2: 1$ in this small study is likely to be due to chance.

Ophthalmic involvement ranges from symptom-free metastasis picked up on imaging (as in case 2) to vision threatening orbital involvement as in cases 1 and 5 . Proptosis was the most common sign in patients with orbital metastasis, being present in four of the six children while five of the six children had either proptosis or periorbital ecchymosis. This is similar to another large series where $75 \%$ of children with orbital metastasis had proptosis or periorbital ecchymosis. ${ }^{4}$
Of the four cases that developed proptosis, only one resulted in blindness, which is similar to that observed by Belgaumi et al. ${ }^{2}$

The role of the ophthalmologist (as seen in this series) towards the disease has been

1. Diagnosis and staging - biopsy of orbital mass (case 1), and staging by virtue of distant spread (all cases);

2. Monitoring and managing visual involvement - planning decompression surgery (case 1), diagnosis/follow-up and management of developing strabismus, for example, patching treatment and surgical plan (cases 3 and 4);

3. Monitoring response to both medical and surgical intervention, for example, stability of proptosis, vision, eye movements, and fundal examination (all cases);

4. Long-term supportive treatment.

Although ophthalmic manifestations are recognised, the disease needs more studies to help contribute to the information bank of the ophthalmic disease spectrum. It seems evident from this series that ophthalmic manifestations can be quite serious requiring aggressive ophthalmic intervention as in case 1. Ophthalmic intervention in the form of mass biopsy was crucial to diagnosis by histopathology from a relatively accessible orbital mass as compared to more internalised primary tumour masses (case 1). On the other hand, it is noteworthy that with the exception of the one complicated case with orbital cellulitis (case 1), visual acuity, proptosis, and other ocular signs remained stable or in fact improved following systemic treatment. This speaks for the response to modern medical treatment agents and suggests that more often than not the ophthalmologist's role is supportive.

\section{References}

1 Goodman MT, Gurney JG, Smith MA, Olshan AF. Sympathetic nervous system tumors. In: Ries LAG, Smith MA, Gurney JG et al. (eds). Cancer Incidence and Survival among Children and Adolescents: United States SEER program 1975-1995, NIH Pub. No. 99-4649. National Cancer Institute: Bethesda, MD, 1999, pp 65-72.

2 Belgaumi AF, Kauffman WM, Jenkins JJ, Cordoba J, Bowman LC, Santana VM et al. Blindness in children with neuroblastoma. Cancer 1997; 80(10): 1997-2004.

3 DuBois SG, Kalika Y, Lukens JN, Brodeur GM, Seeger RC, Atkinson JB et al. Metastatic sites in stage IV and IVS neuroblastoma correlate with age, tumor biology, and survival. J Pediatr Hematol Oncol 1999; 21(3): 181-189.

4 Musarella MA, Chan HS, DeBoer G, Gallie BL. Ocular involvement in neuroblastoma: prognostic implications. Ophthalmology. 1984; 91(8): 936-940.

5 Rudnick E, Khakoo Y, Antunes NL, Seeger RC, Brodeur GM, Shimada $\mathrm{H}$ et al. Opsoclonus-myoclonus-ataxia 
syndrome in neuroblastoma: clinical outcome and antineuronal antibodies - a report from the Children's Cancer Group Study. Med Pediatr Oncol 2001; 36(6): 612-622.

6 Brodeur GM, Seeger RC, Barrett A, Berthold F, Castleberry RP, D'Angio G et al. International criteria for diagnosis, staging, and response to treatment in patients with neuroblastoma. J Clin Oncol 1988; 6: 1874-1881.

7 Matthay KK, Villablanca JG, Seeger RC, Stram DO, Harris RE, Ramsay NK et al. Treatment of high-risk neuroblastoma with intensive chemotherapy, radiotherapy, autologous bone marrow transplantation, and 13-cis-retinoic acid. Children's Cancer Group. N Engl J Med 1999; 341(16): 1165-1173. 